\title{
SOMATOSENSORY EVOKED POTENTIALS OF THE NORMAL HUMAN NEONATE IN REM SLEEP, IN SLOW WAVE SLEEP AND IN WAKING
}

\author{
John E. Desmedt ANd J. ManiL. ${ }^{1}$ \\ Brain Research Unit, University of Brussels, 115 boulecard de Waterloo, Brussels 1000 (Belgium)
}

(Accepted for publication: November 21, 1969)

Neurophysiological contributions to cerebral maturation and to perinatal pathology in man have been mostly concerned with the spontaneous brain activity (Delange et al. 1962; DreyfusBrisac 1962, 1967; Ellingson 1964, 1967; Monod and Pajot 1965; Roffwarg et al. 1966; Parmelee et al. 1967; Prechtl et al. 1968). Studies of the averaged evoked potentials are still in their early days, but they can be expected to extend considerably the scope of the developmental approaches. The potentials evoked by light (Ellingson 1964; Kassabgui et al. 1966; Engel and Benson 1968) or by sound (Barnet and Goodwin 1965; Weitzman et al. 1965; Barnet and Lodge 1966; Ornitz et al. 1967b; Rapin and Graziani 1967) are difficult to evaluate with respect to the primary response components. By contrast, the somatosensory potentials evoked by stimulation of the fingers include the short latency primary response of the contralateral parietal projection and they present characteristic features in the newborn (Desmedt et al. 1967; Manil et al. 1967). One of the features of the newborn response is a prominent initial surface negative component which is not present in the adult. This paper analyses how the somatosensory potentials are influenced in the waking state, in rapid eye movement sleep (REMS) and in slow wave sleep (SWS). At birth spontaneous sleep consists of a succession of REMS and SWS periods which have a fairly equal incidence and which can be accurately identified by established polygraphic criteria (Roffwarg et al. 1966; Parmelee et al. 1967; Prechtl et al. 1968). Clear-cut differences have consistently been found in the evoked potentials averaged during these different behavioural states.

\section{METHODS}

\section{Subjects}

The study is based on thirty-four full-term healthy babies delivered normally after uncomplicated pregnancy ${ }^{2}$. There were twenty-three females and eleven males, aged 26 h to 6 days at the time of the test. The Apgar (1953) index was at least 8 at birth and 10 after $5 \mathrm{~min}$. The weights ranged from 2.9 to $4.4 \mathrm{~kg}$, the head circumference ranged from 32.5 to $35 \mathrm{~cm}$ and the body length varied from 46 to $53 \mathrm{~cm}$. All babies studied presented a normal EEG. Parental consent was obtained in each case.

\section{Stimulation and recording}

The baby was lying quietly in a sound-proof, air-conditioned $\left(24^{\circ} \mathrm{C}, 50 \%\right.$ humidity) shielded room (Hougardy and Desmedt 1967). The stimulating electrodes were silver strips with electrode jelly, placed around the proximal and distal segments of the second, third and fourth fingers of one hand. Each pair of electrodes was connected, with the cathode proximal, to a constant current stimulator which delivered a square pulse of $0.5 \mathrm{msec}$ and 1-6 mA. The current actually flowing through the electrodes was monitored with a Hewlett-Packard model 1111A current probe. A silver plate on the forearm served to connect the baby to earth. For scalp electrodes the usual procedure of skin preparation and

${ }^{1}$ Postgraduate trainee (Aspirant FNRS) 1966-1968.

${ }^{2}$ We wish to thank Prof. P. Hubinont (Department of Obstetrics) for his kind cooperation.

Electroenceph. clin. Neurophysiol., 1970, 29: 113-126 


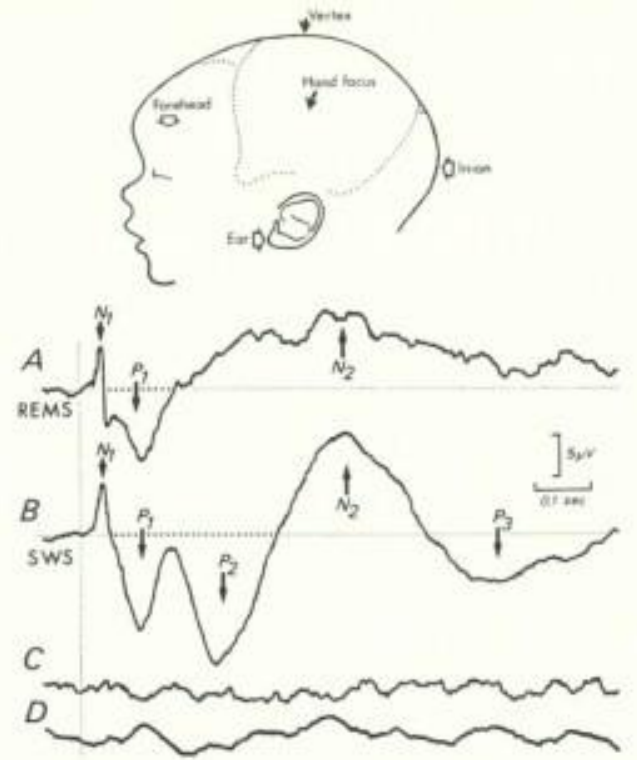

Fig. 1

Lateral view of a newborn head with the contour of the parietal bone and the electrode positions. $A, B$ : characteristic wave forms of averaged cerebral potentials evoked at the contralateral parietal projection by electrical stimulation of the fingers. The proposed nomenclature for evoked potential components is indicated. In this and all other figures, negativity of the active electrode produces an upward movement of the trace. Large horizontal dots indicate duration of initial positive component(s). $C, D$ : same taped data as in $A, B$, but averaged with the Add-Sub mode to show the background noise superimposed on the genuine responses.

fixation of silver discs with adhesive was discarded in favour of very fine sterile stainless steel needles inserted subcutaneously. These needles are well tolerated, less traumatic to the skin and they insure a constant low impedance and a more precise focal recording. The active electrode (negative upwards) was placed over the contralateral parietal projection of the hand (Fig. 1), the focus of which was carefully determined in each baby by a preliminary test with bipolar chains. A vertex electrode was also used. The reference electrodes were placed on the forehead, the ear and the inion. After amplification with a time constant of $0.5 \mathrm{sec}$ the potentials were recorded on an Ampex FR-1300 14-channel FM recorder operated at $15 \mathrm{in}$./sec. A time-coded generator-reader with a precision of $1 \mathrm{sec}$ allowed automatic programming of the start and stop of each run when subsequently reading the data, channel by channel, into a Mnemotron CAT-B or FabriTek FT-1062 computer. Several technical channels of the recorder served to monitor the time of delivery of the stimuli and to identify the various sequences in the runs in which a given parameter (such as the intervals between stimuli) was tested. When useful the data from different runs in a given sleep state, recorded in one session, were pooled during the averaging. The number of samples averaged varied from 32 to 256 . When gross movement artifacts or amplifier overload occurred in any part of a run, the corresponding samples were excluded from the averaging by gating out the taped pulses which normally trigger the computer sweep. The bioelectrical data were also averaged with the Add-Sub mode, in which each sample is alternately added and subtracted (Schimmel 1967): this allows estimation of the noise which is superimposed on the genuine evoked components (Fig. 1, 2).

Data necessary to identify the various sleep stages were recorded on a Grass 6-channel poly-

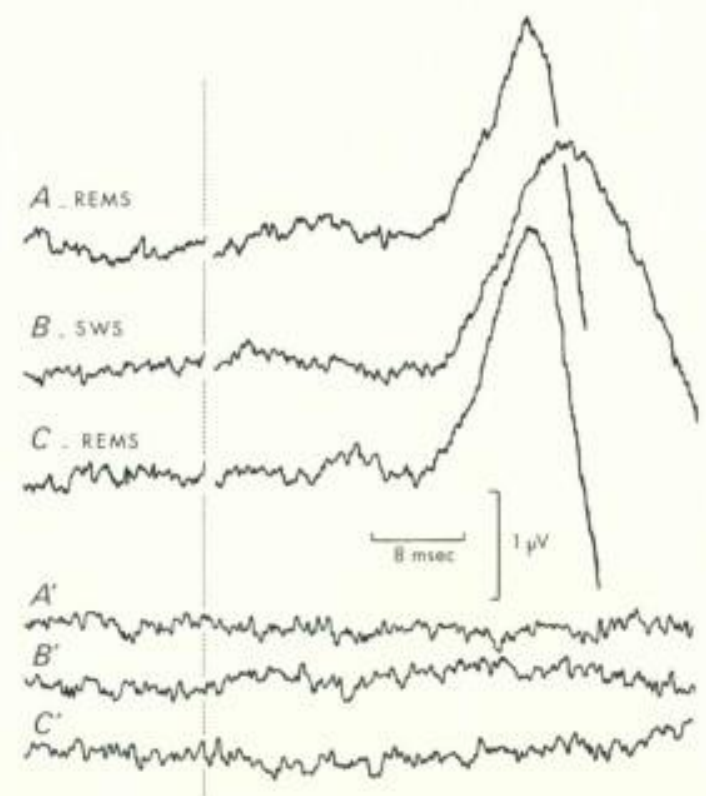

Fig. 2

Male newborn aged 4 days. Evoked potentials recorded at the contralateral parietal focus have been averaged (200 $\mu \mathrm{sec}$ per address) with the usual addition mode in $A$ to $C$, and with the Add-Sub mode in $A^{\prime}$ to $C^{\prime}$. The runs in REMS $(A)$, SWS $(B)$ and another REMS $(C)$ were recorded in that order during the session. 
graph, generally at $6 \mathrm{~mm} / \mathrm{sec}$ (Fig. 5, 8, 9). The electromyogram (EMG) of the submentalis muscle was picked up with two fine needles inserted $1 \mathrm{~cm}$ apart in the chin. The respiration was recorded with a bead thermistor fixed to the face in front of an unobstructed nostril. Since there are no established rules for EEG electrode placements in the newborn (Hellstrom et al. 1963), we used frontal, parietal and vertex bipolar leads. Horizontal and vertical eye movements were recorded through needle electrodes placed on the bridge of the nose, the outer canthus and the upper and lower margins of the orbit. The electrocardiogram, picked up by two chest disc electrodes, was not recorded as such, but its $\mathbf{R}$ spike triggered a pulse which was recorded on the Ampex tape. Subsequent analysis of the heart rate was done with the CAT in the histogram mode,

\section{Procedure}

The babies were brought to the Unit in the early afternoon. After the electrodes had been placed they were bottle-fed and allowed to go undisturbed through their sleep cycles until they woke up some time before the next feed. The strength of the finger stimulus was carefully adjusted to be adequate for evoked potential analysis and yet insufficient to interfere with the natural sequence of sleep states. Synchronous stimulation of three fingers at a lower intensity was better for this purpose than stimulation of a single finger ( $c f$. Debecker and Desmedt 1964). The interval between stimulus was at least $3 \mathrm{sec}$, and in most cases 5-12 sec, in order to avoid interaction between successive responses. Besides monitoring the polygraph record on-line, the baby's face and the bodily and eye movements were closely observed throughout the session, which lasted generally $2 \mathrm{~h}$.

\section{RESULTS}

\section{Identification of sleep and waking states}

This study does not deal with evoked potentials recorded during the periods of transition which occurred as the baby went from one stage of sleep to another. The runs considered were all recorded during typical stages of either REMS or SWS or waking, which could be unambiguously identified by several established criteria.
During the session between two feeds the newborns were sleeping most of the time. Brief waking periods occurred at the beginning and the end of the test, but only five babies presented a sufficiently prolonged and safely identified waking episode to permit adequate analysis of the evoked potentials in that state. Waking was differentiated from REMS chiefly by the open eyes, the characteristics of eye movements, which occurred singly rather than in bursts, the body motility and the generally more regular respiration (Fig. 8).

In the SWS runs the eyes were closed, eye movements were absent, tonic muscle activity appeared in the EMG and the respiration was regular with, in some cases, a superimposed periodicity. There were no bodily movements except for occasional jerks. The EEG disclosed clusters of large slow waves at $0.5-3 \mathrm{c} / \mathrm{sec}$ (tracé alternant, Dreyfus-Brisac et al. 1958) which were best seen in the frontal derivations and actually appeared in the derivations for the electrooculogram (Fig. 5, 9, 10). In the REMS runs the eyes were closed and bursts of eye movements were seen as movements of the eyelids and were recorded on the polygraph; twitches were observed in the face and the extremities and the EMG presented no continuous tonic activity, but occasional bursts; the respiration was irregular both in rate and amplitude, and the EEG showed a low voltage, relatively fast activity (Fig. 5, 6, $8,9)$. The histograms of heart rate, computed off-line, also differed (Fig. 9, D, E) (cf. Prechtl 1968). Mean intervals calculated for 1000 consecutive heart beats in 9 pairs of runs averaged $522 \pm 27 \mathrm{msec}$ in the SWS runs and $497 \pm 43$ msec in the REMS runs. The difference is highly significant $(P<0.001)$. The intervals fluctuated more in REMS, as evidenced by the more dispersed histograms (Fig. 9, D, E and 11, D) and by the larger mean standard deviation.

\section{Nomenclature of evoked response components}

After preliminary tests had elucidated the suitable experimental conditions, characteristic wave forms were consistently recorded in the thirty-four babies here considered. The evoked potentials recorded at the parietal focus are discussed in terms of the simple nomenclature presented in Fig. 1. In the REMS runs the re- 


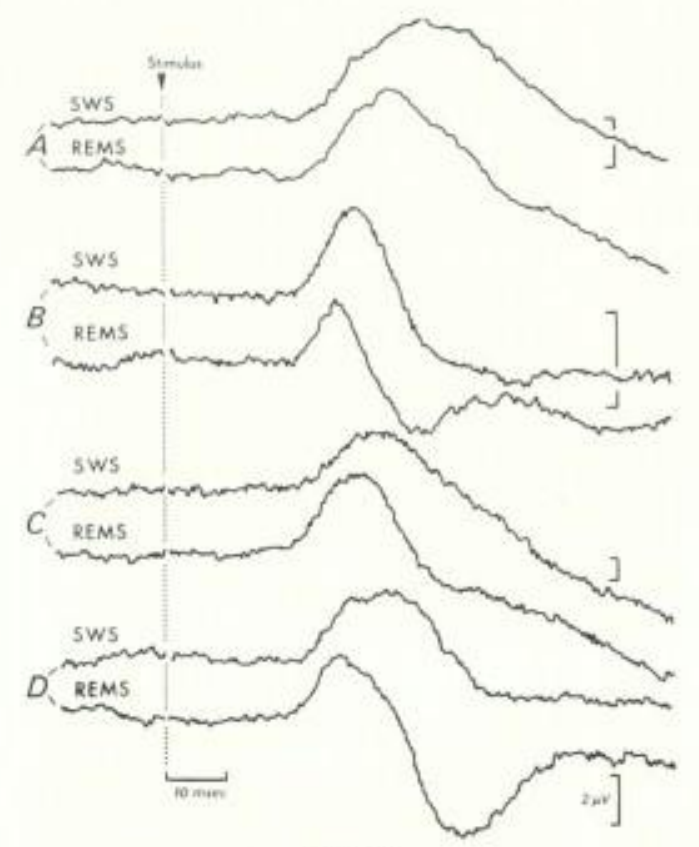

Fig. 3

Pairs of evoked potentials recorded from the contralateral parietal focus either in an SWS run or in an REMS run. The averaging was done with $400 \mu \mathrm{sec}$ per address. $A$ : male (No. 105) aged 5 days. $B$ : female (No. 115) aged 6 days. $C$ : female (No. 121) aged 5 days. D: female (No. 127) aged 6 days. Although the voltage and wave form of the initial negative component $\mathrm{N}_{1}$ vary among the subjects, characteristic changes are seen when the REMS and SWS runs of a given session are compared.

sponse begins with a surface negative wave, called $\mathrm{N}_{1}$, of about $15 \mathrm{msec}$ duration $(A)$. This is followed by a surface positive component, called $P_{1}$, which frequently presents a notch, giving to it a diphasic appearance. $\mathbf{P}_{1}$ is generally followed by a prolonged negative component, $\mathrm{N}_{2}$, which may last for $0.2-1.0 \mathrm{sec}$ and is sometimes followed by a late positive wave, $\mathrm{P}_{3}$ (see Fig. 8, C). In the SWS runs $\mathrm{N}_{1}$ and $\mathrm{P}_{1}$ are also present, but a new positive component called $\mathrm{P}_{2}$ becomes quite prominent after $\mathrm{P}_{1} . \mathrm{P}_{2}$ may be followed by late negative, $\mathrm{N}_{2}$, and late positive, $\mathrm{P}_{3}$, components. Records $C$ and $D$ in Fig. 1 present the same taped samples which have been averaged with the Add-Sub mode. There is only a slight difference in the background noise in REMS $(C)$ and SWS $(D)$ and this cannot account for the difference in the wave forms in $A$ and $B$. The Add-Sub control always failed to disclose any spurious contribution of the background spontaneous activity of our evoked potential samples.

\section{The short latency component $N_{1}$}

The $\mathrm{N}_{1}$ component was analysed by averaging the taped data with a fast sweep, $100-400 \mu \mathrm{sec}$ per address (Fig. 2). In this baby the SWS run was preceded and followed by typical REMS runs. The latency to onset of $N_{1}$ is similar in the two states, while the latency to the peak of $\mathrm{N}_{1}$ and the duration of $\mathrm{N}_{1}$ are larger in the SWS run. The same data averaged with the Add-Sub mode disclose a rather similar noise (notice that the stimulus artifact has been eliminated completely, as expected, by the Add-Sub averaging). Fig. 3 further illustrates the consistent differences of $\mathrm{N}_{1}$ in either SWS or REMS, which are observed even though $\mathrm{N}_{1}$ may vary in voltage or duration in the four different experiments. This comparison has been carried out for 60 pairs of

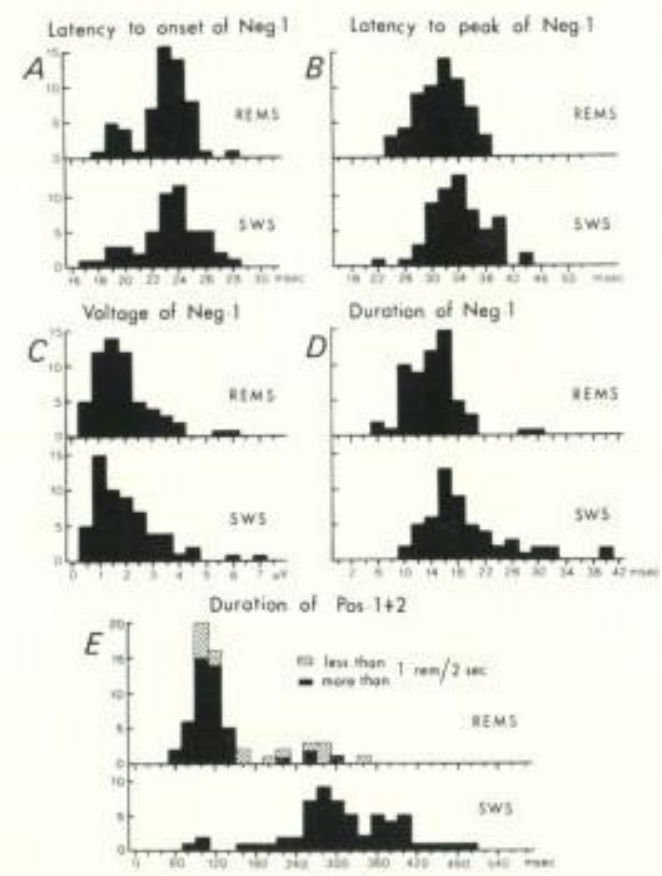

Fig. 4

Histograms of pooled data collected in 60 pairs of runs carried out either in REMS or in SWS stages. $A$ to $D$ deal with the initial negative component $N_{1} . E$ is related to the total duration of the early positivity which includes either $P_{1}$ or $P_{1}$ plus $P_{2}$ when $P_{2}$ is present. The REMS stages are stippled for the runs in which the mean frequency of rapid eye movements is below $0.5 / \mathrm{sec}$. 
TABLE 1

\begin{tabular}{lrrc}
\hline & REMS & SWS & $t$ test \\
\hline $\begin{array}{l}\text { Latency to onset of } \mathrm{N}_{1} \\
\quad \text { (msec) }\end{array}$ & 23.04 & 23.29 & $P=0.18$ \\
$\begin{array}{l}\text { Latency to peak of } \mathrm{N}_{1} \\
\quad 31.4\end{array}$ & 33.9 & $P<0.01$ \\
$\quad$ (msec) & 15.25 & 19.71 & $P<0.01$ \\
$\begin{array}{l}\text { Duration of } \mathrm{N}_{1}(\mathrm{msec}) \\
\text { Voltage of } \mathrm{N}_{1}(\mu \mathrm{V})\end{array}$ & 1.91 & 2.02 & $P=0.08$ \\
\hline
\end{tabular}

runs in typical stages of either REMS or SWS (Fig. 4 and Table I).

\section{The positive components $P_{1}$ and $P_{2}$}

The surface positive component which follows $\mathrm{N}_{1}$ at the parietal focus provides the most consistent feature which distinguishes the two stages of sleep. Fig. 5 illustrates evoked potentials averaged with a rather fast sweep, so that later components are not included. In the REMS run,
$\mathrm{P}_{1}$ has a duration of $120 \mathrm{msec}$ and presents a typical notch which we will not analyse further now $(B, C)$. In the SWS run the first positive deflection corresponds closely in time with $\mathrm{P}_{1}$, seen in REMS, and we can consider them homologous. The $\mathrm{P}_{1}$ of SWS does not present any notch in this instance $(D, E)$ (but see Fig. 6, D). The second positive deflection $P_{2}$ is always present in SWS runs. It is separated from $\mathrm{P}_{1}$ by a ridge which does not reach the baseline in this case, but does so in others (Fig. 7, D, E). These characteristic wave forms are recorded no matter which reference electrode is used (see Fig. 1), either the forehead (Fig. 5, B, D), the inion (Fig. 5, C, E) or the ear. When the separation between $P_{1}$ and $P_{2}$ is incomplete, as in Fig. 5, their respective durations cannot be estimated accurately. Therefore we measured the total duration of the short latency positive component, including both $P_{1}$ and $P_{2}$ when $P_{2}$ was present (horizontal lines with big dots in Fig. 1,6 and 7).

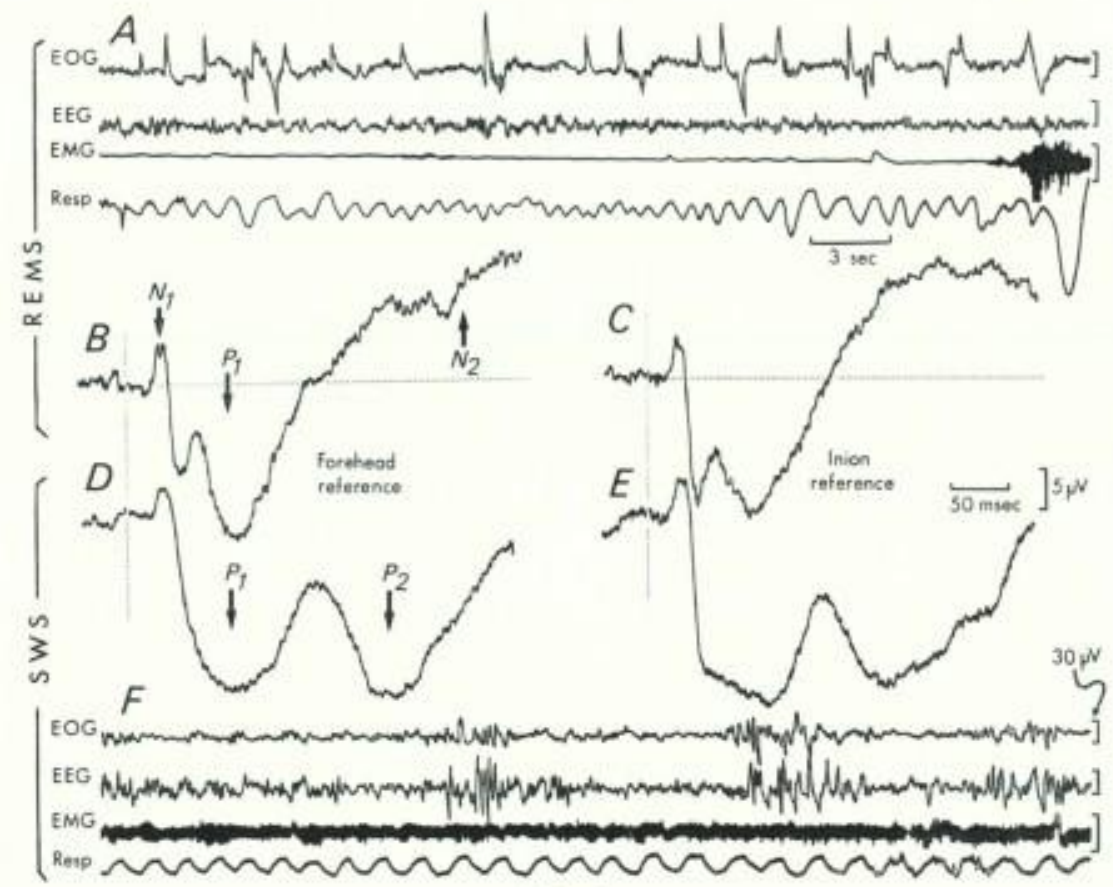

Fig. 5

Female aged 3 days. Polygraph and evoked potential data recorded either in an REMS stage $(A, B, C)$ or in an SWS stage $(D, E, F)$ during the same session. $A$ and $F$ from above downwards; the electrooculogram (EOG), the bipolar EEG between frontal and parietal leads, the EMG of the submentalis muscle and the respirogram. $B, D$ : evoked potentials recorded from the contralateral parietal focus against a forehead reference, $C, E$ : evoked potentials recorded between the same active electrode and an inion reference. 


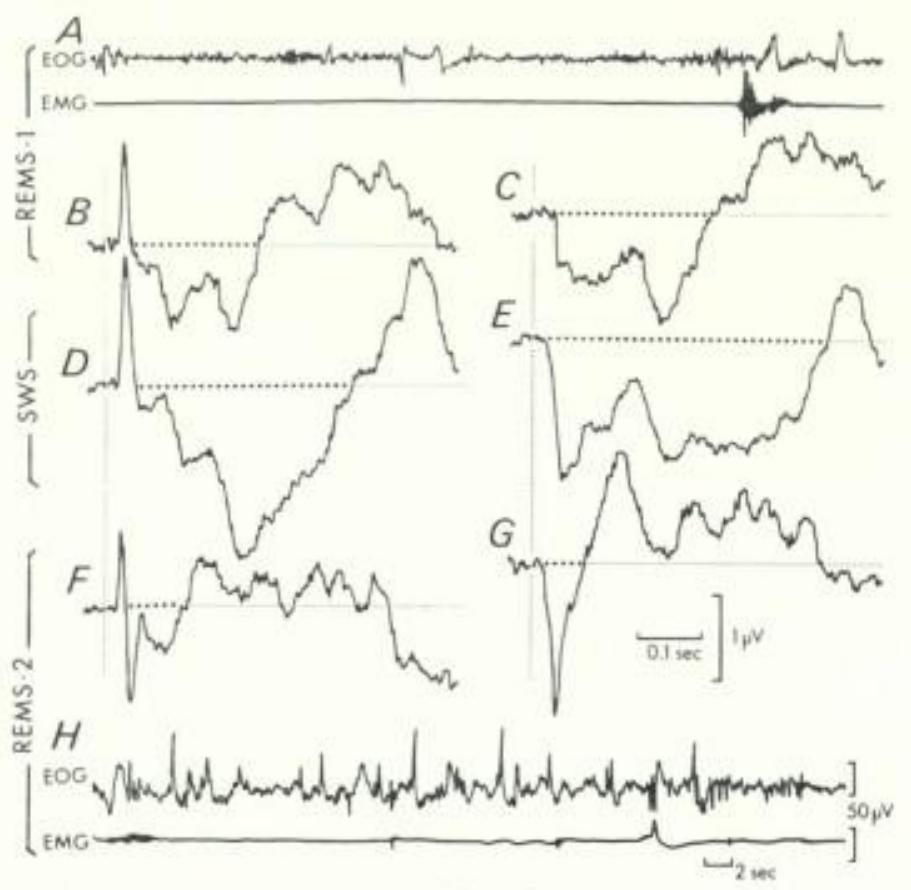

Fig. 6

Female aged 5 days. The evoked potentials recorded in two different REMS stages and in an SWS stage during the same session are compared. $A, B, C$ : REMS stage with a mean frequency of rapid eye movements of $0.3 / \mathrm{sec} . F, G, H$ : REMS stage with a mean frequency of rapid eye movements of $1.4 / \mathrm{sec}, B, D, F$; evoked potentials recorded between the contralateral parietal focus and a forehead reference electrode, $C, E, G$ : evoked potentials simultaneously recorded $3 \mathrm{~cm}$ in front of the parietal focus and in which the early positive component, but not the initial negativity is observed.

Pooled data for the 59 pairs of runs (Fig. 4, E) give a mean total duration of $310 \mathrm{msec}$ in the SWS runs and of $132.6 \mathrm{msec}$ for the REMS runs, the difference being highly significant $(P<0.001)$. Only 3 durations are below $140 \mathrm{msec}$ in SWS, while 13 durations are above $140 \mathrm{msec}$ in REMS. We wondered whether these unusual instances might be related to any feature of the corresponding sleep stages. The criteria used (see above) leave no ambiguity as to the REMS or SWS nature of the runs included in this study. However, it is possible to distinguish among the REMS runs on the basis of the frequency of rapid eye movements. Fig. 6 compares for the same session 2 REMS in both of which irregular respiration, the small amplitude fast EEG and loss of muscle tone with occasional abrupt bursts are present. The mean frequency of rapid eye movements is $0.3 / \mathrm{sec}$ in the first (Fig. 6, $A-C$ ) and $1.4 / \mathrm{sec}$ in the second run (Fig. $6, F-H$ ). The positive component in $B$ lasts longer than usual for REMS, $200 \mathrm{msec}$, while in $F$, it is reduced to a $P_{1}$ of $87 \mathrm{msec}$ duration. Both responses in REMS differ clearly from the SWS positivity which lasts $335 \mathrm{msec}(D)$. Similar differences are seen in the potentials $C, E$ and $G$ which were picked up $3 \mathrm{~cm}$ anteriorly from the parietal focus and include the positive, but not the $\mathrm{N}_{1}$, component (Manil et al. 1967).

Fig. 7 shows in another baby that intermediate patterns can be seen between a typical REMS response with $\mathrm{P}_{1}$ only $(B)$, and the characteristic SWS response with a prominent $\mathrm{P}_{2}(E)$. Thus the emergence or the elimination of $\mathrm{P}_{2}$ during the transition from one sleep stage to another is not an all-or-none process. More intermediate values would no doubt have been recorded if we had included data on atypical or intermediate stages of sleep. In the histograms of Fig. 4, $E$ the data for REMS are represented in stipple for the runs in which the frequency of rapid eye movements was below $0.5 / \mathrm{sec}$; this rather low rate in otherwise typical REMS runs occurred in 9 of the 13 instances with a positive duration 


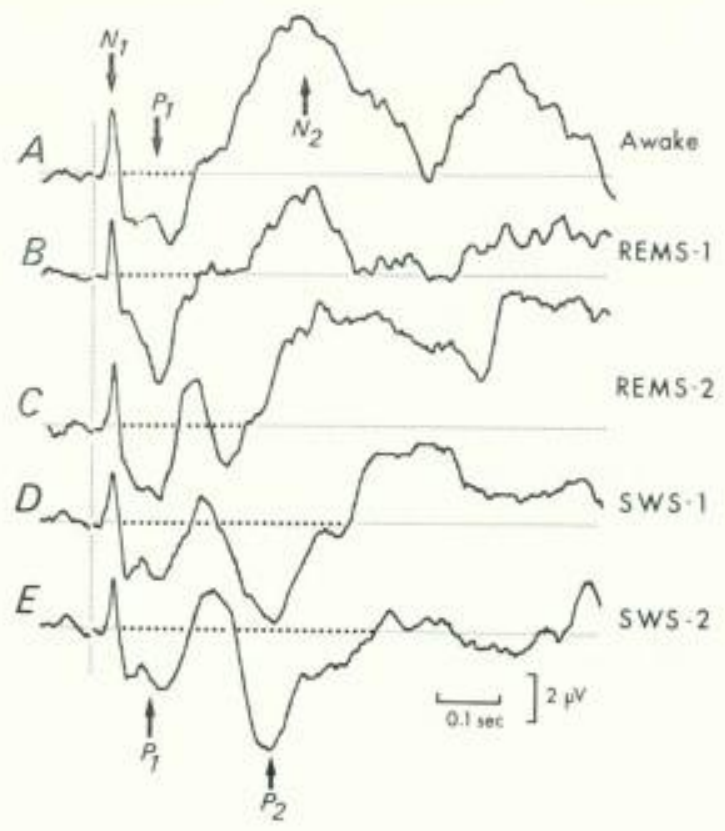

above $140 \mathrm{msec}$, but in only 7 of the 46 instances with a positive duration below $140 \mathrm{msec}$. Thus the frequency of rapid eye movements appears relevant, at least to some extent, as an index to evaluate the REMS influence on the early positive component of the evoked potentials.

\section{The waking state}

The components $\mathrm{N}_{1}$ and $\mathrm{P}_{1}$ had similar forms in REMS and in the waking state (Fig. 7, $A, B)$. This appears also in Fig. $8, B, D$ with a faster sweep. The background noise is generally

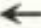

Fig. 7

Male aged 6 days. Evoked potentials recorded from the contralateral parietal focus with a forehead reference. $A$ : waking run which occurred at the end of the sleep cycles before the next feed. $B, C$ : two REMS runs; $D, E$ : two SWS runs recorded during the same session. The evoked potentials have been ranked in the order of increasing duration of the early positivity (thicker horizontal dotted line). They illustrate the progressive emergence of a $P_{2}$ component in SWS.

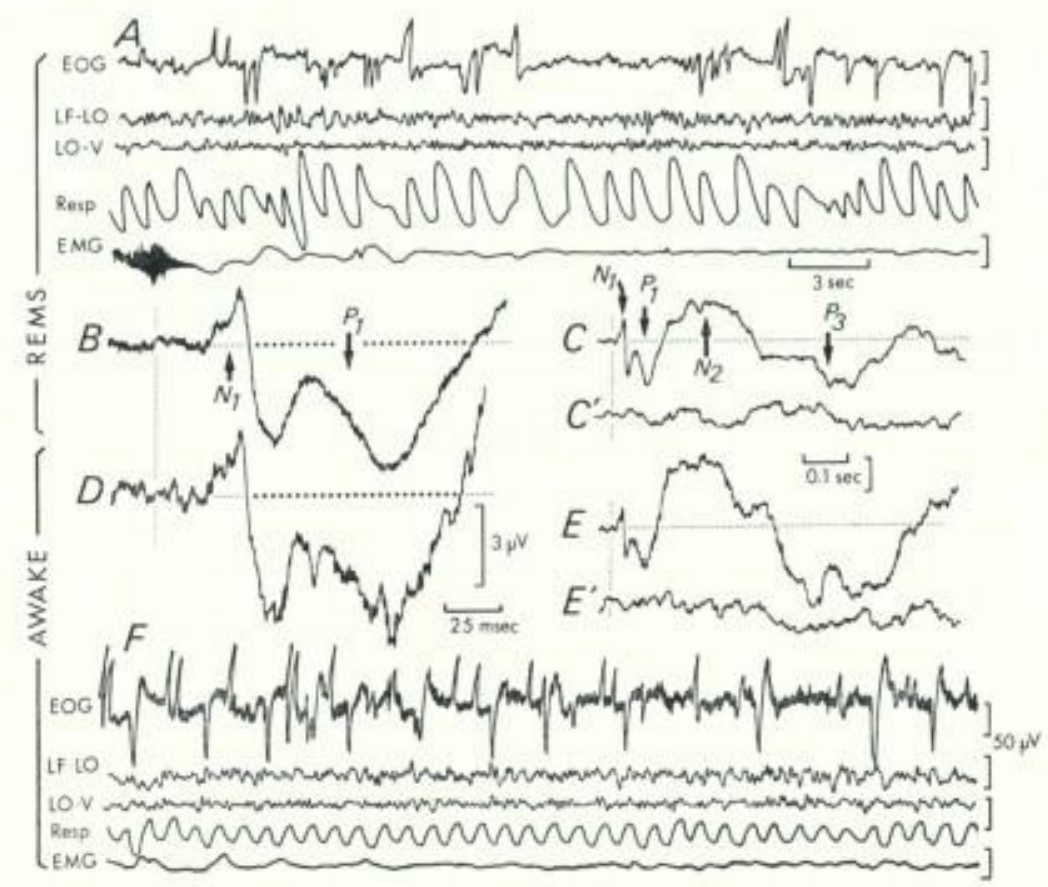

Fig. 8

Female aged 4 days. Comparison of polygraph and evoked potential data in an REMS run and in a waking run recorded after a feed before the sleep cycles. $A$ to $F$ from above downwards: the EOG, the EEG recorded from forehead-occipital region (LF-LO) and occipital region-vertex (LO-V) with bipolar leads, the respirogram and the EMG of the submentalis muscle. The evoked potentials recorded at the contralateral parietal focus are presented both on a fast $(B, D)$ and a slow sweep $(C, E)$, the latter with Add-Sub controls $\left(C^{\prime}, E^{\prime}\right)$. The $\mathrm{P}_{2}$ component is absent from both stages. 
more important in the waking run, due to movements of the newborn. The duration of $\mathrm{P}_{1}$ (thicker dotted line) is $100 \mathrm{msec}$ in $B$ and 95 msec in $D$ and these figures correspond to typical REMS values (Fig. 4, E). The subsequent $\mathrm{N}_{2}$ wave was as a rule larger in the waking runs (Fig. 8, C, E). A late $\mathrm{P}_{3}$ component might or might not be present. Our data suggest that the evoked potential wave form in waking corresponds to that in very activated REMS.

\section{Comparison with vertex potentials}

The potentials evoked by the same stimulus at the vertex were routinely recorded on FM tape. Fig. 9 documents SWS and REMS runs with typical responses at the somatosensory projection in $B$ and $F$. In $C$, the vertex response in SWS presents two positive components which correspond in time to $P_{2}$ and $P_{3}$. The latency to the peak of $\mathrm{P}_{2}$ was measured in 32 runs in the different newborns: its mean value was 280.5 msec at the parietal focus (Fig. 10, A) and 285.6 msec at the vertex (Fig. 10, B). This difference is not significant $(P=0.6)$ and it may be proposed that the components with $\mathrm{P}_{2}$ features are related to a common electrogenesis. Fig. 11, $F, G$ illustrates other vertex responses in SWS, with $P_{2}$ here followed by a negative wave. The $P_{3}$

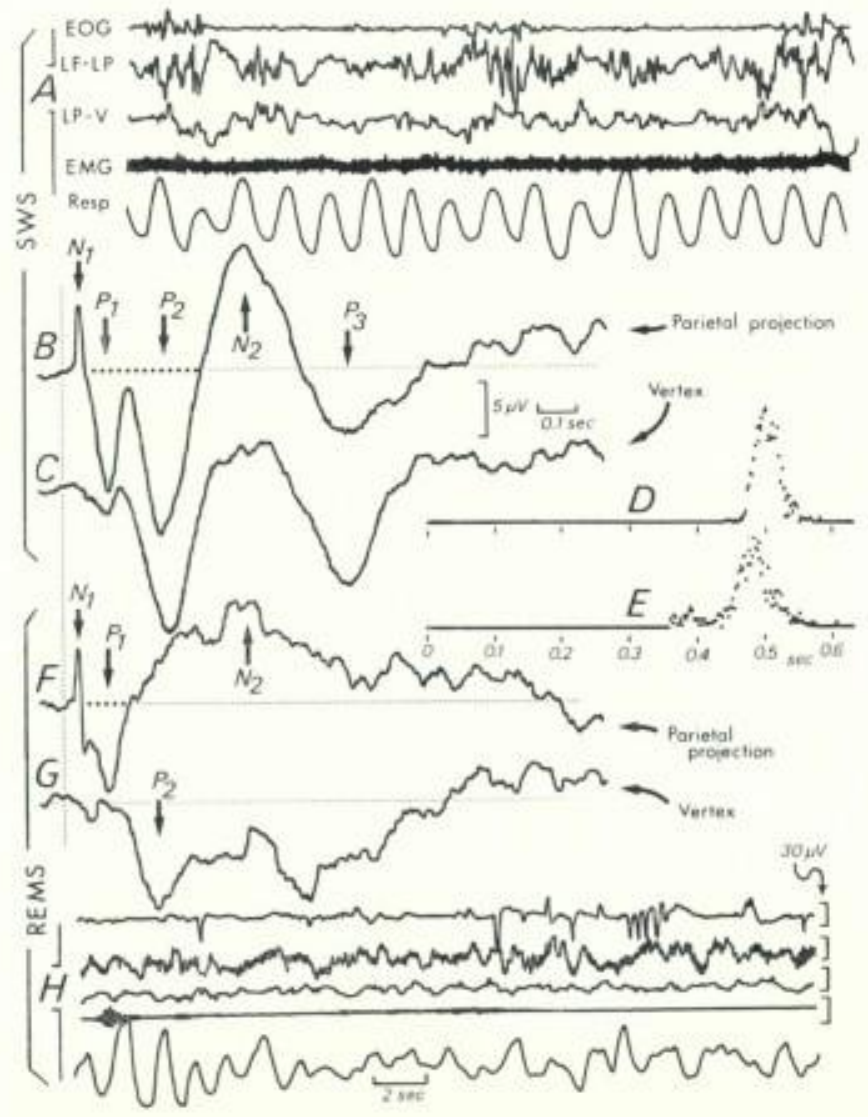

Fig. 9

Male aged 3 days. Comparison of polygraph and evoked potential data in an SWS run and in an REMS run recorded in the same session. $A$ to $H$, from above downwards: the EOG, the EEG from fronto-parietal and parieto-vertical bipolar leads (time constant $0.3 \mathrm{sec}$ ), the EMG of the submentalis muscle and the respirogram. $D, E$ : interval histograms of 1000 successive heart beats in the SWS $(D)$ and the REMS $(E)$ runs. $B, F$ : evoked potentials recorded from the contralateral parietal focus. $C, G$ : evoked potentials recorded simultaneously from the vertex. 
component, which is indeed more variable both at the vertex and at the parietal projection, will not be analysed here.

In the REMS runs the vertex response presented a similar wave form, but its voltage and peak latency were reduced (Fig. 9, G). For 30 pairs of runs in either sleep stage the mean amplitude of $\mathrm{P}_{2}$ at the vertex was $5.2 \mu \mathrm{V}$ in SWS (Fig. 10, D) and $3.1 \mu \mathrm{V}$ in REMS (Fig. 10, $E)$. This difference is highly significant $(P<0.001)$. The mean latency to the peak of $\mathrm{P}_{2}$ at the vertex for 32 pairs of runs was $285.6 \mathrm{msec}$ in SWS (Fig. 10, B) and $239 \mathrm{msec}$ in REMS (Fig. 10, C) $(P<0.001)$. The vertex wave form was thus quite different from that of the parietal potential in REMS (Fig. 9, $F, G$ ).

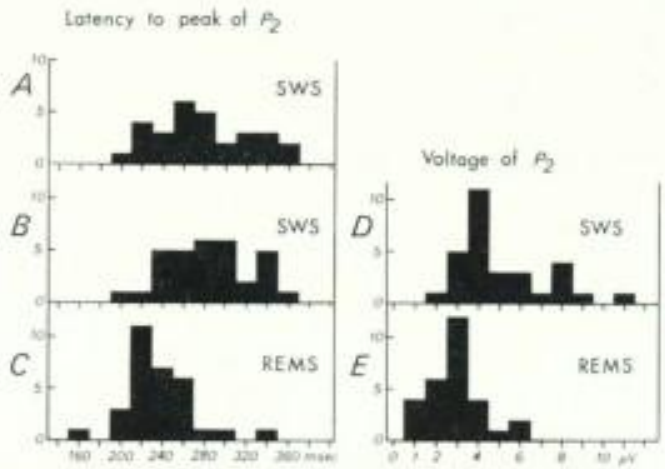

Fig. 10

Histograms of the latency to the peak of component $\mathbf{P}_{2}$ recorded at the contralateral parietal focus in SWS runs $(A)$, and at the vertex in SWS runs ( $B$ ) or in REMS runs (C). D, E: histograms of the voltage of component $\mathrm{P}_{2}$ recorded at the vertex in SWS runs $(D)$ and in REMS runs (E). Pooled data from 30 or 32 pairs of runs either in SWS or in REMS.

\section{The intervals between stimuli}

In this study it appeared essential to ensure long enough intervals between successive stimuli, particularly in the SWS runs. This parameter was investigated in 14 experiments by programming a number of sequences of, say, 10-15 stimuli delivered alternately at two or more selected intervals; subsequently all the evoked potential samples corresponding to any such interval in either SWS or REMS were averaged together. This procedure minimizes the influence of any trend in the experimental conditions during sleep stages. Fig. 11 illustrates for an
SWS run responses elicited at either 12 or $8 \mathrm{sec}$ intervals and recorded from the parietal focus and from the vertex with respect to several references. Little, if any, difference in wave form can be related to these long intervals, except for a slight increase of $\mathrm{N}_{2}$ at $8 \mathrm{sec}$ (Fig. 11, A, F). The $\mathrm{P}_{2}$ component is slightly larger at $8 \mathrm{sec}$ at the vertex in $F$, but not in $G$, and it is slightly smaller at $8 \mathrm{sec}$ in $A, B$ and $C$. The minor differences between the two potentials in $C$ have been analysed by averaging each group of samples in an alternate mode in which samples 1, 3, 5, 7, $9, \ldots$ and samples $2,4,6,8,10, \ldots$ are added separately. The method can be further sophisticated by comparing, for instance, samples 1,2,5, $6,9,10, \ldots$ with samples $3,4,7,8,11,12, \ldots$ etc., and it gives some clue to the variability among the samples recorded under similar conditions. Comparison of the records in $H$ and $I$ suggests that there is as much variation among the samples at a given interval as between the samples at the two intervals considered. It is difficult to detect small significant differences in the wave form at large intervals but it can be said that in SWS the responses do not appear to interact for intervals between stimuli of 15 to 10 $\mathrm{sec}$. Intervals of $8 \mathrm{sec}$ appear to be at about the limit and intervals of 4 or $3 \mathrm{sec}$ definitely induce changes in the potentials, especially in their late components. This is not the case in REMS in which intervals of 3-4 sec may not disclose any evidence of sequential interaction.

\section{Age of subjects}

No significant differences were found in the potentials recorded from newborns on their first and on their sixth days. The clinically accepted "newborn" period indeed extends over the first week.

\section{Discussion}

Consistent results were obtained in the thirtyfour newborns because many of the relevant parameters had been identified in preliminary studies. The active electrode should be placed at the focus of the contralateral hand projection on the scalp to record the prominent initial surface negative component of the parietal gyrus (cf. Desmedt et al. 1967; Manil et al. 1967). No

Electroenceph, clin. Neurophysiol., 1970, 29: 113-126 


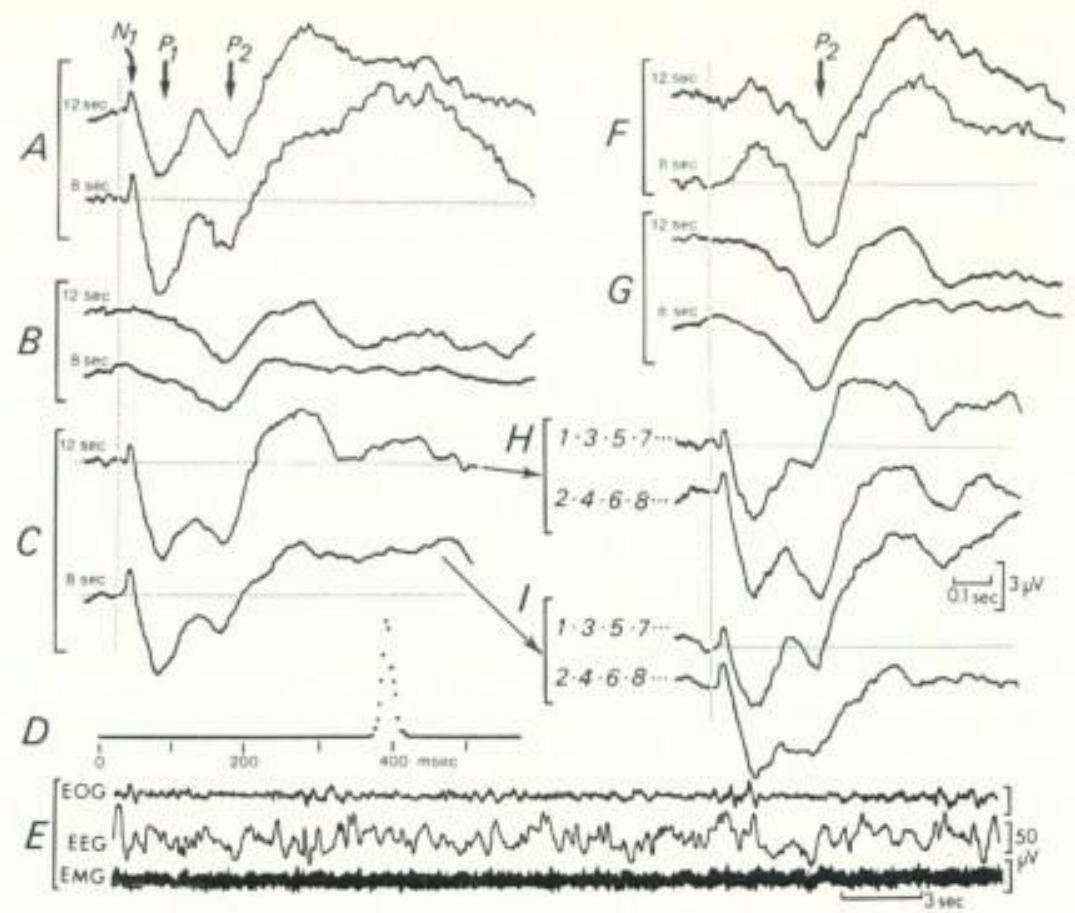

Fig. 11

Female aged 6 days. Comparison of the evoked potentials elicited at regular intervals of either $12 \mathrm{sec}$ or $8 \mathrm{sec}$, in an SWS run. The responses are recorded from the contralateral parietal focus against an ear $(A)$ or forehead $(C, H, I)$ reference, from the ipsilateral parietal region against a forehead $(B)$ and from the vertex against an inion $(F)$ or forehead reference $(G)$. $D$ : histogram of intervals between 1000 consecutive heart beats. $E$ : polygraph data with the EOG, EEG (fronto-parietal bipolar leads) and the submentalis EMG.

difference appeared consistently among the responses simultaneously recorded between the focus and any of the reference electrodes used (Fig. 5, B-E and 11, A, C) but this point might deserve closer investigation. Finger stimuli were used to elicit a rather homogeneous corticipetal volley of skin and joint afferents (Dawson 1956). By contrast, stimulation of mixed nerves would have excited motor nerve fibres and muscle afferents as well, thereby producing a complex heterogeneous input to the brain. The intensity of the electrical pulses to the fingers was adequate to evoke all the relevant components of the responses, but not strong enough to disturb the newborn and upset the natural cycling of SWS and REMS periods. The interval between stimuli was at least $3 \mathrm{sec}$ and generally $5-12 \mathrm{sec}$ to avoid interaction between successive responses. This is important because the critical intervals at which interaction starts is larger in SWS than in REMS. Comparison between responses would be distorted at intervals such as $2 \mathrm{sec}$, which would alter the wave forms in SWS but not much so in REMS.

We analysed the cerebral responses recorded either in characteristic REMS runs, satisfying all the criteria of this well defined stage (Roffwarg et al. 1966), or in genuine SWS runs with tracé alternant, tonic submentalis EMG, with no eye or bodily movements except for occasional jerks and with regular respiration (Fig. 5, 8, 9) (cf. Roffwarg et al. 1966; Parmelee et al. 1967; Prechtl et al. 1968). The interval histograms of heart beats also present different characteristics in the two sleep stages (Fig. 9, D, E and 11, D). We have excluded from consideration in the present study the transition periods between one stage of sleep to another, and the periods with untypical sleep, since our problem was not to study the organization of sleep for itself, or the detailed gradation of sleep sequences. The human newborn offers better opportunities than the

Electroenceph, clin. Neurophysiol., 1970, 29:113-126 
adult for studies on evoked potentials in stages of REMS and SWS. Newborns spend more time in sleep and in REMS. They also present normal sleep cycles during the day (Aserinsky and Kleitman 1955) and quickly go into sleep with the electrodes on after a feed.

The characteristic features described for the evoked potentials in the REMS and the SWS stages are related to changes of brain physiology associated with the sleep stages as such, rather than to the time elapsed from sleep onset, a possibility mentioned by Ornitz et al. (1967a). The sleep cycles between two feeds generally include several periods of REMS and SWS succeeding each other (Roffwarg et al. 1966); the evoked potentials do not present significant differences in, say, the first and the second REMS periods, provided both periods are equally typical (Fig. 2). In other words, it is not the rank of any sleep stage during the recording session, but rather its intrinsic features, which appear to be correlated with the changes in evoked potential wave form.

The latency of the initial $\mathrm{N}_{1}$ component does not change significantly between REMS and SWS runs (Fig. 2 and $4, A$ ). In the cat with chronically implanted electrodes the cerebral potentials evoked by nerve stimulation present a $4 \%$ mean reduction in latency in REMS (Dagnino et al. 1966) and such a small change may have been missed in our data. The latency to the peak of $\mathrm{N}_{1}$ and the duration of $\mathrm{N}_{1}$ are both significantly reduced in REMS runs as compared with SWS runs (Fig. 2, 3 and 4, B, $D$; Table 1). These observations, and also the rather long duration of $\mathrm{N}_{1}(15-20 \mathrm{msec})$, make it clear that the $\mathrm{N}_{1}$ component of the newborn involves post-synaptic activities within the cerebral cortex.

The voltage of $\mathrm{N}_{1}$ does not differ significantly in the two sleep stages (Table I) and we also failed to observe any consistent differences for the voltage of the early positive component (Fig. 4, $C$ and 5). In the cat REMS is associated with an increase of voltage of the short latency components of the cerebral potentials evoked either by acoustic clicks (Teas and Kiang 1964) or by stimulation of the visual pathway (Dagnino et al. 1965; Walsh and Cordeau 1965; Baldissera et al. 1966) or by stimulation of peripheral nerves (Favale et al. 1963; Okuma and Fujimori 1963; Albe-Fessard et al. 1964; Allison 1965; Favale et al. 1965; Allison et al. 1966). These effects appear to result mainly from facilitation of thalamic relay transmission since the cortical responses to direct radiation or callosal stimulation are rather similar in REMS and SWS (Dagnino et al. 1965; Walsh and Cordeau 1965; Baldissera et al. 1966; Allison and Goff 1968). However, the evidence obtained in adult man differs from that of cat studies, since the early surface positive "primary" response evoked by nerve stimulation is there described as smaller in REMS than in SWS (Goff et al. 1966). Our observations on the newborn are also at variance with the data for the cat.

The most consistent and obvious change in the evoked potentials as the newborn goes into SWS is the appearance of a new component, $\mathrm{P}_{2}$, after $P_{1}$ (Fig. 5, 7, 9). This results in a marked increase in the total duration of the initial positivity of the response in SWS (Fig. 4, E). The emergence of $\mathrm{P}_{2}$ is not an all-or-none phenomenon (Fig. 7) and abortive $\mathrm{P}_{2}$ components can be present in intermediate stages, or even occasionally in otherwise typical REMS runs, and particularly in those with a lower incidence of rapid eye movements (Fig. 4, E). The component $\mathrm{P}_{2}$ is well developed at the vertex (Fig. 9), where it indeed persists with a smaller voltage and a slightly reduced latency in the REMS runs (Fig. $10)$. During the latter, $P_{2}$ has generally disappeared at the parietal focus so that a remarkable dissociation can be seen between the two recording sites in REMS (Fig. 9). It can be suggested that $\mathrm{P}_{2}$ is generated at a midline region and that this activity increases and expands in SWS. A later positive $\mathrm{P}_{3}$ component is also more developed during SWS, but its variability has so far precluded detailed analysis. Our observations are in line with the known enhancement in SWS of the late non-specific components of cerebral potentials, evoked either by clicks (man: Williams et al. 1962; Guilbaud et al. 1965; Weitzman and Kremen 1965; Suzuki and Taguchi 1968) or by stimulation of peripheral nerves (cat: Okuma and Fujimori 1963; Albe-Fessard et al. 1964; Allison et al. 1966; man: Goff et al. 1966).

Though less extensive, our data suggest that the evoked potential wave form in the waking

Electroenceph, clin. Neurophysiol., 1970, 29:113-126 
state resembles that in REMS: the voltage and configuration of $\mathrm{N}_{1}$ and $\mathrm{P}_{1}$ are similar and the component $\mathrm{P}_{2}$ is lacking. Component $\mathrm{N}_{2}$ may be larger in the waking state (Fig. 7, 8). When assessing these results it should be remembered that our responses were averaged during a fairly prolonged state of relatively quiet waking and that they would not disclose features associated with the abrupt arousal from sleep. In the latter condition, potentials can be markedly potentiated (Bremer and Stoupel 1959; Dumont and Dell 1960; Desmedt 1960, p. 160) but, as Walsh and Cordeau (1965) rightly pointed out, such arousal effects are to be differentiated from those of steady state waking.

\section{SUMMARY}

Averaged cerebral potentials evoked by electrical stimulation of the fingers were investigated in thirty-four full-term normal human newborns. The stimuli were delivered at intervals of at least $3 \mathrm{sec}$ and generally $5-12 \mathrm{sec}$ to avoid sequential interactions between the responses. They were of adequate intensity to evoke consistent responses both at the contralateral parietal projection and at the vertex, but did not interfere with the normal cycles of Slow Wave Sleep (SWS) and of Rapid Eye Movement Sleep (REMS). The sleep stages were identified by a number of established criteria: pattern of respiration, eye, face and limb movements, spontaneous EEG, submental EMG and also by the histogram of heart beat intervals (Fig. 5, 8, 9, 11).

The somatosensory evoked potentials present genuine and consistent features in typical REMS and SWS runs. The mean latency and voltage of the initial surface negative component, $\mathrm{N}_{1}$, which is characteristic of the newborn response but is no longer developed in the adult, do not differ significantly in the two sleep stages (Fig. 2, 3). The latency to the peak and the duration of $\mathrm{N}_{1}$ are significantly increased in SWS (Fig. 4). The positive component $P_{1}$ which follows $N_{1}$ is recorded in both sleep stages. However, a second component $\mathrm{P}_{2}$ is present only in SWS and it provides the most typical feature of that stage of sleep (Fig. 1, 5, 7, 9). As a result, the total duration of the positive deflection is much longer in SWS than in REMS (Fig. 4, E). Late negative
$\mathrm{N}_{2}$ and positive $\mathrm{P}_{3}$ components are also influenced by the sleep stages. Interesting correlations appear between the evoked potentials recorded at the hand projection and at the vertex (Fig. 9, 10). In waking the evoked potentials appear rather similar to those in activated REMS (Fig. $7,8)$.

The evoked somatosensory potentials in newborns permit a consistent analysis of both "primary" and late components of the cerebral responses and the sleep stages represent one of the major parameters to be considered in their investigation.

\section{RÉSUMÉ}

LES POTENTIELS ÉVOQUÉS SOMESTHÉSIQUES DU NOUVEAU-NÉ AU COURS DU SOMMEIL ET DE LA VEILLE

Les potentiels cérébraux évoqués par la stimulation électrique des doigts de la main ont été analysés chez trente-quatre nouveau-nés humains normaux à terme. Les intervalles entre les stimuli étaient supérieurs à $3 \mathrm{sec}$ et dans la plupart des cas de 5-12 sec pour éviter les interactions entre les réponses successives. Leur intensité était suffisante pour évoquer des réponses cohérentes à la fois au niveau du foyer de la projection pariétale contralatérale et au niveau du vertex; elle n'interférait cependant pas avec le déroulement normal des cycles de sommeil lent (SWS) et de sommeil paradoxal avec mouvements rapides des yeux (REMS). Les stades de sommeil ont été identifiés par plusieurs critères classiques: l'allure du respirogramme, des mouvements des yeux et de la face et des membres, l'activité EEG. l'EMG du muscle sous-mentonnier et aussi l'histogramme des intervalles entre battements cardiaques (Fig. 5, 8, 9, 11).

Les potentiels évoqués somesthésiques présentent des caractères particuliers dans les stades typiques de sommeil calme ou de sommeil paradoxal. La latence et le voltage de la composante initiale surface-négative, $\mathrm{N}_{1}$, qui est caractéristique de la réponse chez le nouveau-né et est absente chez l'adulte, ne diffèrent pas de façon significative dans les deux stades de sommeil (Fig. 2, 3). La latence du sommet de $N_{1}$ et la durée de $\mathrm{N}_{1}$ augmentent de façon significative dans le sommeil lent (Fig. 4). La composante

Electroenceph, clin. Neurophysiol., 1970, 29: 113-126 
positive $\mathrm{P}_{1}$ qui suit immédiatement $\mathrm{N}_{1}$ apparait également dans les deux stades de sommeil, Cependant une seconde composante positive $\mathrm{P}_{2}$ n'est enregistrée qu'en sommeil lent et elle constitue en fait l'élément le plus caractéristique de ce stade (Fig. 1, 5, 7, 9). La durée totale de l'électrogenèse positive du début est ainsi beaucoup plus longue en sommeil lent qu'en sommeil paradoxal (Fig. 4, E). Les composantes tardives négative $\mathrm{N}_{2}$ et positive $\mathrm{P}_{3}$ sont aussi influencées par les stades de sommeil. Des corrélations intéressantes apparaissent entre les potentiels enregistrés au foyer pariétal et au vertex (Fig. 9, 10). Chez le nouveau-né éveillé les potentiels évoqués ressemblent à ceux d'un stade de sommeil paradoxal très activé (Fig. 7, 8).

Chez le nouveau-né, les potentiels évoqués somesthésiques permettent ainsi d'analyser de façon cohérente à la fois les composantes "primaires" et tardives des réponses cérébrales. Les stades de sommeil représentent un des paramètres les plus importants à considérer dans leur étude.

This research has been supported by grants from the Office of Naval Research U.S. Navy, from the National Institute of Neurological Diseases and Stroke, National Institutes of Health, U.S. Public Health Service, and by the Belgian Fonds de la Recherche Scientifique Médicale.

\section{REFERENCES}

Alae-Fessard, D., Massion, J,, Hall, R, et Rosenblith, W. Modifications au cours de la veille et du sommeil des valeurs moyennes de réponses nerveuses centrales induites par des stimulations somatiques chez le chat libre. C. R. Acad. Sci. (Paris), 1964, 258; 353-356.

Alusson, T. Cortical and subcortical evoked responses to central stimuli during wakefulness and sleep. Electroenceph. clin. Neurophysiol., 1965, 18: 131-139.

ALıison, T. and GoFF, G. D. Potentials evoked in somatosensory cortex to thalamocortical radiation stimulation during waking, sleep and arousal from sleep. Arch. ital. Biol., 1968, 106: 41-60.

Aluson, T., Goff, W. R, and Sterman, M. B. Cerebral somatosensory responses evoked during sleep in the cat. Electroenceph. clin. Neurophysiol., 1966, 2I: $461-468$

APGAR, V. A proposal for a new method of evaluation of the newborn infant. Curr. Res. Anesth., 1953, 32: 260-267.

ASERINSKY, E. and KLEITMAN, N. A motility cycle in sleeping infants as manifested by ocular and gross bodily activity, $J$. appl. Physiol., 1955, $8: 11-18$.

Baldissera, F., Cesa-Bianchi, M. G. and Mancia, M. Responses of visual cortex to transcallosal and geniculate stimulations during sleep and wakefulness. Arch. ital. Biol., 1966, 104: 247-262.

BARNET, A. B. and Goodwin, A. M. Averaged evoked electroencephalographic responses to clicks in the human newborn. Electroenceph. clin. Neurophysiol., 1965, 18: 441-450.

BARNet, A. B. and LODGE, A. Diagnostic in infancy of prenatal rubella deafness using computer averaged EEG responses to sound. J.Pediat., 1966,69: 753-758.

Bremer, F, et Stoupel, N. Facilitation et inhibition des potentiels évoqués corticaux dans l'éveil cérébral. Arch. int. Physiol. Biochim., 1959, 67: 240-275.

Dagnino, N., Favale, E., Loeb, C. and Manfredi, M. Sensory transmission in the geniculostriate system of the cat during natural sleep and arousal. $J$. Neurophysiol., 1965, 28: 443-456.

Dagnino, N., Fayale, E., Loeb, C., Manfredi, M. and SerruN, A. Accelerated synaptic transmission in nucleus ventralis-postero-lateralis during deep sleep. Experientia (Basel), 1966, 22: 329-330.

DAwson, G. D. The relative excitability and conduction velocity of sensory and motor nerve fibres in man. $J$. Physiol. (Lond.), 1956, 131: 436-451.

DeBecker, J. et Desmedr, J. E. Les potentiels évoqués cérébraux et les potentiels de nerf sensible chez Thomme et l'utilisation de l'ordinateur numérique Mnemotron 400-B. Acta neurol. belg., 1964, 64: 1212-1248.

Delange, M., Castain, P., Cadlihac, J, et Passouant, P. Les divers stades du sommeil chez le nouveau-né et le nourrisson. Rev, neurol,, 1962, 107: 271-276.

DEsMeDT, J. E. Neurophysiological mechanisms controlling acoustic input. In G, L. RASMussen and W, F. WINDLE (Eds.), Neural mechanisms of the auditory and vestibular systems. Thomas, Springfield, III., 1960: 152-164.

Desmedt, J. E., Manil, J., Chorazyna, H. et Debecker, J. Potentiel évoqué cérébral et conduction corticipète pour une volée d'influx somesthésique chez le nouveau-né normal. C. R. Soc. Biol. (Paris), 1967, 161: 205-209.

Dreyfus-Brisac, C. The electroencephalogram of the premature infant. Wld Neurol, 1962, 3: 5-15.

Dreyfus-Brisac, C. Ontogénèse du sommeil chez le prématuré humain: étude polygraphique. In A. MrNkowski (Ed.), Regional development of the brain in early life. Blackwell, Oxford, 1967: 437-457.

Dreyfus-Brisac, C., Samson, D., Bl.anc, C. et Monod, N. L'EEG chez l'enfant normal de moins de 3 ans. Êtud. néo-natal., 1958, 7: 143-175.

Dumont, S. et Delt, P. Facilitation réticulaire des mécanismes visuels corticaux. Electroenceph. clin. Neurophysiol., 1960, 12: 769-796.

ELIINGSON, R. J. Studies of the electrical activity of the developing human brain. In W. A. НrмwicH and H. E. Hiswich (Eds.), Progress in brain research. The developing brain. Elsevier, Amsterdam, 1964, 9: 26-53.

ELLiNGSON, R, J. Methods of recording cortical evoked responses in the human infant. In A. Minkowski (Ed.). Regional development of the brain in early life, Blackwell, Oxford, 1967: 413-435.

Electroenceph, clin. Neurophysiol., 1970, 29: 113-126 
ENGel, R. and Benson, R. C. Estimate of conceptional age by evoked reponse activity. Biol. Neonat. (Basel), $1968,12: 201-213$.

FAVAle E., LOEB, C. and MANFredr, M. Somatic evoked responses in cats during natural sleep. Experientia (Basel), 1963, 19: 1-3.

Favale, E., Loeb, C., Manfred, M. and Sacco, G. Somatic afferent transmission and cortical responsiveness during natural sleep and arousal in the cat. Electroenceph, clin. Neurophysiol, 1965, 18: 354-368.

Goff, W. R., Aluison, T., Shaptro, A. and Rosner, B. S. Cerebral somatosensory responses evoked during sleep in man. Electroenceph. clin. Neurophysiol., 1966, 2I: $1-9$.

Guilbaud, G., Rosenblith, W., Burns, S. et AlbeFrssare, D. Évolution chez Thomme au cours des différents stades du sommeil des réponses électrocorticales évoquées au vertex par deux modes de stimulation. C. R. Acad. Sci. (Paris), 1965, 260: $5366-5369$.

Hellstrom, B., Karlsson, B. and Mússichler, H. Electrode placement in EEG of infants and its anatomical relationship studied radiographically, Electroenceph. clin. Neurophysiol., 1963, I5: 115-117.

Hougardy, J. and Desmed, J, E. Sound-proofed rooms for experimentation in sensory physiology. Arch. int. Physiol. Blochim., 1967, 75: 352-353.

Kassabgut, M. El, Cadilhac, J. et Passouant, P. Études des réponses évoquées visuelles à l'état de veille et au cours de sommeil chez l'enfant. Rev, neurol., 1966, III: $84-88$,

Manil, J., Desmedt, J. E., DFbecker, J, et Chorazyna, H. Les potentiels cérébraux évoqués par la stimulation de la main chez le nouveau-né normal. Rev, neurol., 1967, 117: 53-61.

Monod, N. et PAjot, N. Le sommeil du nouveau-né et du prématuré. 1. Analyse des études polygraphiques (mouvements oculaires, respiration et EEG) chez le nouveau-nê à terme, Biol, Neonat. (Basel), 1965, 8: 281-307.

OкuмA, T. and Fusımori, M. Electrographic and evoked potential studies during sleep in the cat. Folia psychiat. neurol. jap., 1963, 17: 25-50.

Ornitz, E, M., Ritvo, E. R., CARr, E. M., LA Franchi, S. and WALter, R. D. The effect of sleep onset on the auditory averaged evoked response. Electroenceph. clin. Neurophysiol., 1967a, 23: 335-341.

Ornitz, E. M., Ritvo, E. R., Carr, E, M., Panman, L. M. and WALtER, R. D. The variability of the auditory averaged evoked response during sleep and dreaming in children and adults. Electroenceph. clin. Neurophysiol., 1967b, 22:514-524.

Parmelee, A. H., Wenner, W. H., Akiyama, Y., Stern, E. and FLescher, J. Electroencephalography and brain maturation. In A. MinkowsKI (Ed.), Regional development of the brain in early life. Blackwell, Oxford, 1967: 459-480.

Prechth, H. F. R. Polygraphic studies of the full-term newborn: II. Computer analysis of recorded data. In M. BAX and R. C. MAcKfrrH (Eds.), Studies in infancy. Clinic in Detelopmental Medicine No. 27, S.I.M.P. Heinemann, London, 1968: 22-40.

Prechtl, H. F. R., AKIYAMA, Y., ZINKIN, P. and Grant, D. K. Polygraphic studies of the full-term newborn: I. Technical aspects and qualitative analysis. In M. BAX and R. C. MAcKertH (Eds.), Studies in infancy. Clinic in Developmental Medicine No. 27, S.I.M.P. Heinemann, London, 1968: 1-21.

RAPIN, I, and Graziani, L. Auditory-evoked responses in normal, brain-damaged and deaf infants. Neurology (Minneap.), 1967, 17: 881-894.

Roffwarg, H. P., Muzio, J. N. and Dement, W. C. Ontogenic development of the human sleep-dream cycle. The prime role of "dreaming sleep" in early life may be in the development of the central nervous system. Science, 1966, 152: 604-619.

Schimmet, H. The $( \pm)$ reference: accuracy of estimated mean components in average response studies. Science, 1967, 157: 92-93.

SuzuKI, T. and TAGUCHI, K. Cerebral evoked response to auditory stimuli in young children during sleep. Ann. Otol. (St. Louis), 1968, 77: 102-110.

TE.AS, D. C. and KIANG, N. Y. Evoked responses from the auditory cortex. Exp. Neurol., 1964, 10:91-119.

Walsh, J, T. and Cordeau, J. P. Responsiveness in the visual system during various phases of sleep and waking. Exp. Neurol., 1965, 11: 80-103.

Wertzman, E. D, Fishaein, W. and Graziani, L. Auditory evoked responses obtained from the scalp electroencephalogram of the full-term neonate during sleep. Pediatrics, 1965, 35: 458-462.

Wertzman, E, D. and Kremen, H. Auditory evoked responses during different stages of sleep in man. Electroenceph. clin. Neurophysiol, 1965, 18: 65-70.

Williams, H. L., Tepas, D. I. and Morlock, H. C. Evoked responses to clicks and electroencephalographic stages of sleep in man. Science, 1962, 138: 685-686.

Reference: DesmeDt, J. E. and MANIL, J. Somatosensory evoked potentials of the normal human neonate in REM sleep, in slow wave sleep and in waking. Electroenceph. clin. Neurophysiol., 1970, 29: 113-126. 